\title{
ANALISIS TINGKAT KERAWANAN TANAH LONGSOR MENGGUNAKAN METODE FREKUENSI RASIO DI DAERAH ALIRAN SUNGAI BIALO
}

\author{
Analysis of the Landslides Vulnerability Level Using Frequency Ratio Method in
} Bialo Watershed

\author{
Nurul Fadilah ${ }^{1 \otimes}$, Usman $^{\text {Arsyad }^{2}}$, Andang Suryana Soma ${ }^{2}$ \\ ${ }^{1}$ Mahasiswa Laboratorium Pengelolaan Daerah Aliran Sungai, Fakultas Kehutanan, Universitas Hasanuddin, Makassar \\ 2 Staf Pengajar, Laboratorium Pengelolaan Daerah Aliran Sungai, Fakultas Kehutanan, Universitas Hasanuddin, Makassar \\ corresponding author: fadilahusaipa432@gmail.com
}

\begin{abstract}
Landslide is a movement of soil with slope direction and moves it on a slide. This study aimed to predict the landslide susceptibility map by using a frequency ratio. It used seven causative factors, such as slope, curvature, land use, lithology, distance to a river, distance to lineament, and rainfall. The result showed the AUC of success rate and predicted rate produced high accuracy with 0.907 and 0.904 , respectively. According to the frequency ratio, the slope was the most influential than the other causative factors with 7.15. The landslide susceptibility divided into five classes, i.e. very low, low, moderate, high, and very high. Landslide susceptibility with very high and high was $19 \%$. Moreover, classes susceptibility of very low, low, and moderate were $71 \%$. The presentation of very high and high susceptibility is low, but it was located on an upper stream, and it will be a danger if to the downstream.
\end{abstract}

Key words: landslide, frequency ratio, Bialo watershed

\section{A. PENDAHULUAN}

Indonesia merupakan negara dengan tingkat kerawanan bencana yang tinggi, terutama bencana hidrometeorologi. Berdasarkan tren kejadian bencana di Indonesia selama 10 tahun terakhir (2008-2017), tercatat bahwa terjadi tanah longsor sebanyak 4.174 kejadian dengan korban jiwa sebanyak 1.775 (Badan Nasional Penanggulangan Bencana, 2018).

Tanah longsor merupakan bencana alam yang menjadi pusat perhatian dikarenakan bencana ini terjadi secara kontinyu dari tahun ke tahun, serta merupakan bencana alam yang paling banyak menimbulkan kerugian baik berupa materi maupun korban jiwa (Nusantara \& Setianto, 2015). Tanah longsor ini merupakan bencana yang berpengaruh besar terhadap kehidupan serta keselamatan manusia. Sejak tahun 2008 hingga tahun 2017, tercatat telah terjadi 55 kejadian tanah longsor di Sulawesi Selatan yang mengakibatkan 38 orang meninggal dunia atau hilang (Badan Nasional Penanggulangan Bencana, 2018).

Terdapat beberapa faktor yang berpengaruh pada tanah longsor yaitu aspek kemiringan, jarak dari sungai, jarak dari patahan, litologi, jenis tanah, tutupan lahan, dan presipitasi (Pradhan \& Lee, 2010).

Pemetaan bahaya longsor dapat dilakukan dengan metode kuantitatif, salah satu metode yang dapat digunakan adalah frekuensi rasio. Frekuensi rasio didasarkan kepada hubungan antara lokasi kejadian tanah longsor dan faktor-faktor yang mempengaruhi terjadinya longsor (Nusantara \& Setianto, 2015). Frekuensi Rasio adalah rasio antara area kejadian longsor terhadap total area dan juga rasio probabilitas kejadian longsor terhadap ketidakjadian longsor untuk faktor atribut yang diberikan (Lee et al., 2006 dalam Handayani \& Singarimbun, 2016).

Daerah Aliran Sungai (DAS) Bialo merupakan daerah yang sering mengalami kejadian bencana tanah longsor. Berdasarkan hasil Inventarisasi awal di Daerah Aliran Sungai Bialo terdapat beberapa titik longsor dan bekas longsor yang dipicu oleh beberapa faktor baik faktor alam maupun faktor yang disebabkan oleh manusia. DAS Bialo terletak di dua kabupaten, yaitu Bantaeng dan Bulukumba, Provinsi Sulawesi Selatan yang secara geografis terletak di $05^{\circ} 21^{\prime} 0^{\prime \prime}$ - 05 $5^{\circ} 4^{\prime} 0^{\prime \prime}$ Lintang Setatan dan $119^{\circ} 55^{\prime} 0^{\prime \prime}$ - 120 $13^{\prime} 0^{\prime \prime}$ Bujur Timur. DAS Bialo memiliki luas $114 \mathrm{~km}^{2}$ atau 11.400 ha (Tanika et al., 2013). Oleh karena itu, perlu dilakukan penelitian untuk menganalisis tingkat kerawanan longsor di DAS Bialo dengan menggunakan metode frekuensi rasio. Penelitian ini bertujuan untuk mengetahui jumlah titik lokasi tanah longsor periode tahun 2004-2014 di DAS Bialo, mengetahui faktor yang paling berpengaruh terhadap terjadinya tanah longsor berdasarkan nilai frekuensi rasio di DAS Bialo, dan mengklasifikasikan daerah rawan tanah 
longsor berdasarkan metode frekuensi rasio. Penelitian ini diharapkan menjadi sumber informasi bagi instansi terkait dalam upaya melakukan tindakan-tindakan mitigasi bencana tanah longsor di DAS Bialo.

\section{B. METODE PENELITIAN}

\section{Waktu dan Tempat}

Penelitian ini dilaksanakan selama 4 bulan yaitu bulan November tahun 2018 sampai dengan Februari tahun 2019. Lokasi penelitian terletak di DAS Bialo yang secara administratif terletak Kabupaten Bantaeng dan Kabupaten Bulukumba, Provinsi Sulawesi Selatan. Pengolahan data dilakukan di Laboratorium Pengelolaan Daerah Aliran Sungai, Fakultas Kehutanan Universitas Hasanuddin.

\section{Alat dan Bahan}

Alat yang digunakan dalam penelitian ini, yaitu laptop dengan perangkat lunak sistem informasi geografis aplikasi ArcMap 10.3 dan SPSS (Statistical Product and Service Solution), kamera, alat tulis menulis. Bahan yang digunakan dalam penelitian ini, yaitu peta batas DAS Bialo, Citra Landsat 7 Tahun 2003, DEM Nasional Resolusi 0.27 arcsecond (8,1 meter) tahun 2014, Peta Geologi Lembar Ujung Pandang, Benteng, dan Sinjai, Sulawesi skala 1:250.000, Data Curah Hujan BMKG periode tahun 2004 - 2014, Citra time series dari Google Earth Pro rentang tahun 2004-2014 untuk inventarisasi longsor.

\section{Pengumpulan Data}

Pengumpulan atau pengolahan data menggunakan ArcGIS 10.3 dalam membuat data spasial inventarisasi tanah longsor dan juga faktor-faktor penyebab tanah longsor. Data yang diperoleh tersebut selanjutnya dibagi menjadi dua, yakni data training sebanyak $80 \%$ data yang digunakan untuk memprediksi besar pengaruh setiap faktor terhadap kejadian longsor. Sementara itu, dua puluh persen sisanya digunakan untuk validasi hasil prediksi tersebut

\section{Inventarisasi Longsor}

Inventarisasi longsor didapatkan melalui survey lapangan dan interpretasi citra. Survey lapangan didapatkan dengan metode random sampling seperti pada Gambar 1 dan interpretasi citra penginderaan jauh dengan rentang tahun 2004- 2014 didapatkan melalui citra time series Google Earth Pro berdasarkan karakteristik spektral, bentuk, dan kontras (Kanungo et al., 2006 dalam Soma \& Kubota, 2017). Wilayah studi terbatas di bagian hulu DAS Bialo, dengan jumlah tanah longsor yang teridentifikasi sebanyak 216 poligon. Gambar 1 adalah contoh penampakan longsor dari dua titik sampling longsor. Data longsor yang didapatkan berasal dari digitalisasi resolusi tinggi dengan pencitraan deret waktu dari Google Earth Pro ke ArcGIS 10.3, kemudian file-file ini disimpan sebagai format yang kompatibel dengan GIS sebagai $(. \mathrm{kml})$. Kemudian, data itu diubah lagi menjadi bentuk file dan menjadi raster format $10 \mathrm{~m} \times 10 \mathrm{~m}$.

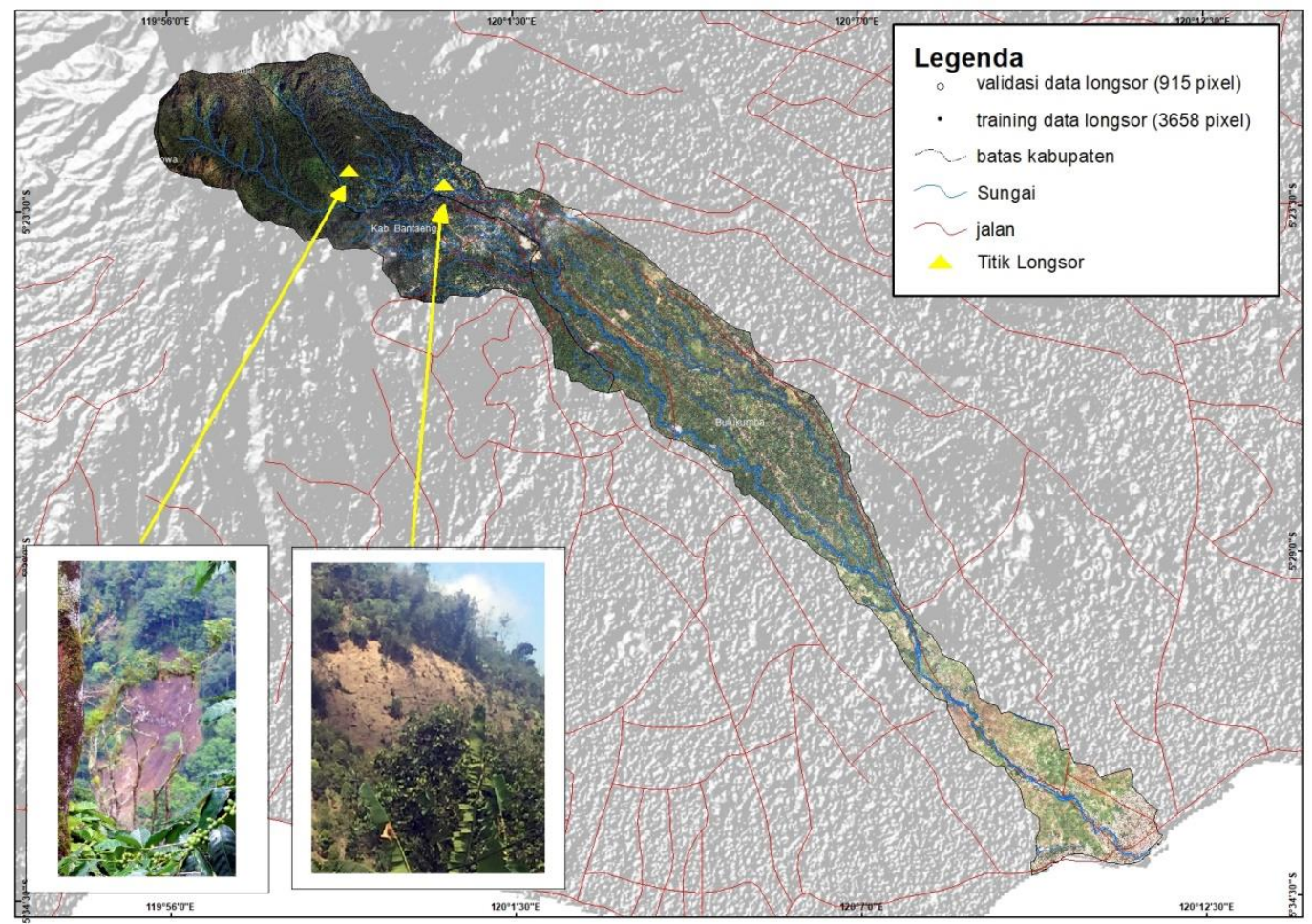

Gambar 1. Peta inventarisasi longsor 


\section{Faktor Penyebab Tanah Longsor}

Faktor-faktor penyebab kemudian dikategorikan berdasarkan pengetahuan umum dan ketersediaan data di lokasi penelitian (Soma \& Kubota, 2017). Faktor tersebut antara lain data kemiringan lereng, data jarak dari sungai, data jarak dari patahan, penutupan lahan, data litologi, data curah hujan, dan data kurvatur. Faktor kemiringan lereng dan data faktor jarak dari sungai didapatkan dari DEM Nasional, khusus data jarak

dari sungai dihitung dengan buffering analisis garis aliran. Data jarak dari patahan/sesar dan data litologi didapatkan dari peta geologi 1:250.000 yang diperoleh dari Lembaga Penelitian Geologi. Data terkait faktor penutupan lahan diperoleh dari interpretasi citra Landsat 7 tahun 2003. Faktor curah hujan didapatkan dengan membuat peta polygon Thiessen. Data-data curah hujan periode tahun 2004 - 2014 terakhir didapatkan dari Badan Metereologi, Klimatologi dan Geofisika (BMKG) Wilayah IV Makassar yang kemudian. Data curvature atau lengkungan permukaan bumi didapatkan dari DEM Nasional.

\section{Analisis Data}

Analisis data menggunakan metode kuantitatif, yaitu metode frekuensi rasio. Frekuensi rasio adalah nilai perbandingan antara area kejadian longsor dan total area berdasarkan faktor penyebabnya. Jika rasio lebih besar dari 1,0 maka hubungan antara kejadian longsor dan faktor penyebabnya lebih tinggi, dan jika rasio kurang dari 1,0 maka hubungan antara kejadian longsor dan faktor penyebabnya rendah (Lee \& Lee, 2006 dalam Soma dan Kubota, 2017). Nilai rasio di setiap kelas menunjukkan tingkat hubungan nilai frekuensi rasio yang dihitung dengan rumus (Soma \& Kubota, 2017):

$$
F r=\frac{P x c L(n m) / \sum P n x L}{\text { Pixel }(n m) / \sum P n x}
$$

Di mana: Fr adalah frekuensi rasio; PxcL adalah jumlah pixel dengan tanah longsor didalam kelas' $\mathrm{n}$ dari parameter $\mathrm{m}(\mathrm{nm})$; Pixel adalah jumlah pixel di kelas $n$ dari parameter $\mathrm{m}(\mathrm{nm})$; $\sum \mathrm{PnxL}$ adalah total piksel dari parameter $\mathrm{m}$; dan $\Sigma P n x$ adalah keseluruhan piksel dari area.

Untuk membuat Landslides Suspectibility Index (LSI) atau indeks kerentanan tanah longsor, semua faktor penyebab dipetakan dalam bentuk peta raster dari nilai $\mathrm{Fr}$ kemudian dijumlahkan dengan menggunakan rumus (Soma \& Kubota, 2017):

$\mathrm{LSI}=\mathrm{Fr}_{1}+\mathrm{Fr}_{2}+\ldots .+\mathrm{Fr}_{\mathrm{n}}$,

Di mana: $\mathrm{Fr}_{1}, \mathrm{Fr}_{2}$, dan $\mathrm{Fr}_{\mathrm{n}}$ adalah peta raster frekuensi rasio untuk faktor penyebab longsor.

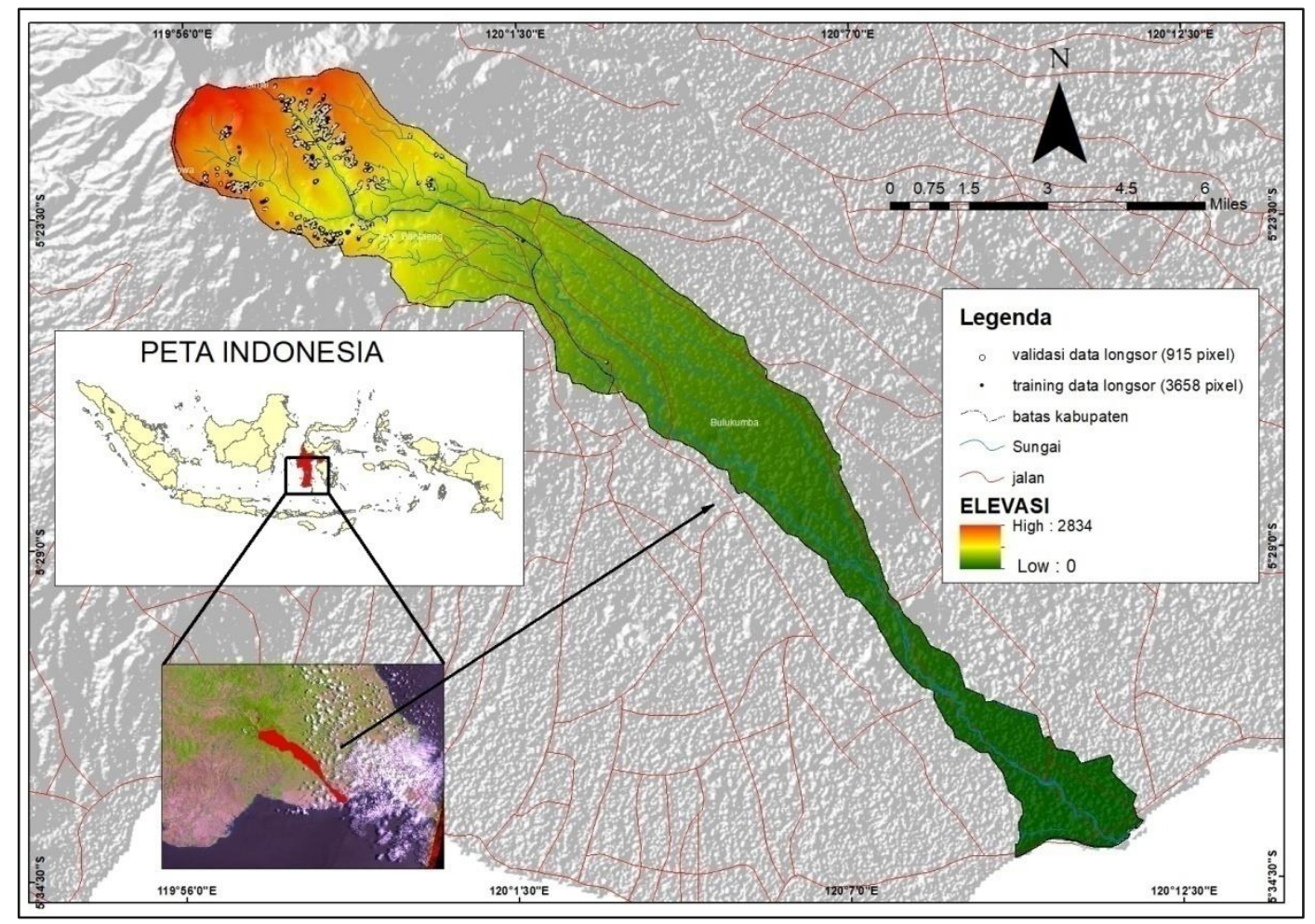

Gambar 2. Peta distribusi longsor 


\section{Validasi Data}

Hasil dari analisis kerentanan longsor, kemudian divalidasikan menggunakan data kejadian longsor yang telah didapatkan. Validasi ini menunjukkan seberapa baik model dalam memprediksi longsor. Hasil validasi ini memperlihatkan nilai akurasi prediksi berdasarkan AUC (Area Under Curve) melalui analisis (Receiver Operating Characteristic) dengan menggunakan software SPSS. Setiap kelas LSI dihitung persentase jumlah longsor dan persentase komulatifnya. Kurva perubahan laju dibuat dengan Nilai LSI sebagai sumbu $x$ dan persentase komulatif kejadian longsor sebagai sumbu y (Nusantara \& Setianto, 2015). Klasifikasi hasil validasi longsor kemudian dikelompokkan menjadi beberapa rentang nilai yaitu 0,5 0,6 dinayatakan gagal, 0,6-0,7 dinyatakan buruk, 0,7 0,8 dinyatakan cukup, 0,8 - 0,9 dinyatakan baik, dan $\quad 0,9$ - 1 dinyatakan sangat baik (Rasyid et.al, 2016 dalam Soma \& Kubota, 2018). Peta kerawanan tanah longsor yang telah dihasilkan kemudian diklasifikasikan menjadi 5 kelas yaitu sangat rendah, rendah, sedang, tinggi, sangat tinggi.

\section{HASIL DAN PEMBAHASAN}

Hasil inventarisasi tanah longsor didapatkan melalui interpretasi citra penginderaan jauh dengan rentang tahun
2004 - 2014 berdasarkan karakteristik spektral, bentuk, dan kontras (Kanungo et al., 2006 dalam Soma \& Kubota, 2017). Berdasarkan data longsor dari 2004 hingga 2014 dengan menggunakan fotografi udara Google Earth Pro menunjukkan jumlah tanah longsor yang diidentifikasi sebanyak 216 poligon. Hasil data tersebut yang sebelumnya sudah diubah menjadi data raster, dibagi menjadi dua yaitu data training $(80 \%)$ sebanyak 3.658 pixel dan data validasi $(20 \%)$ sebanyak 915 pixel. Peta kejadian longsor tahun 2004-2014 di DAS Bialo dapat dilihat pada Gambar 2.

Frekuensi Rasio digunakan untuk mengetahui tingkat kerawanan tanah longsor berdasarkan faktor-faktor penyebab terjadinya longsor. Faktor-faktor yang dihitung menggunakan metode analisis frekuensi rasio meliputi kelerengan, kurvatur, litologi, penutupan lahan, jarak dari sungai, jarak dari patahan/sesar, dan curah hujan

\section{Karakteristik Kerentanan Tanah di DAS Bialo}

Faktor-faktor penyebab yang menjadi variabel dalam peneltian ini diantaranya kemiringan lereng, kurvatur, litologi, penutupan lahan, jarak dari drainase/saluran air/sungai, jarak dari patahan/sesar, dan curah hujan. Peta faktor-faktor penyebab tanah longsor beserta kelasnya dapat dilihat pada Gambar 3.

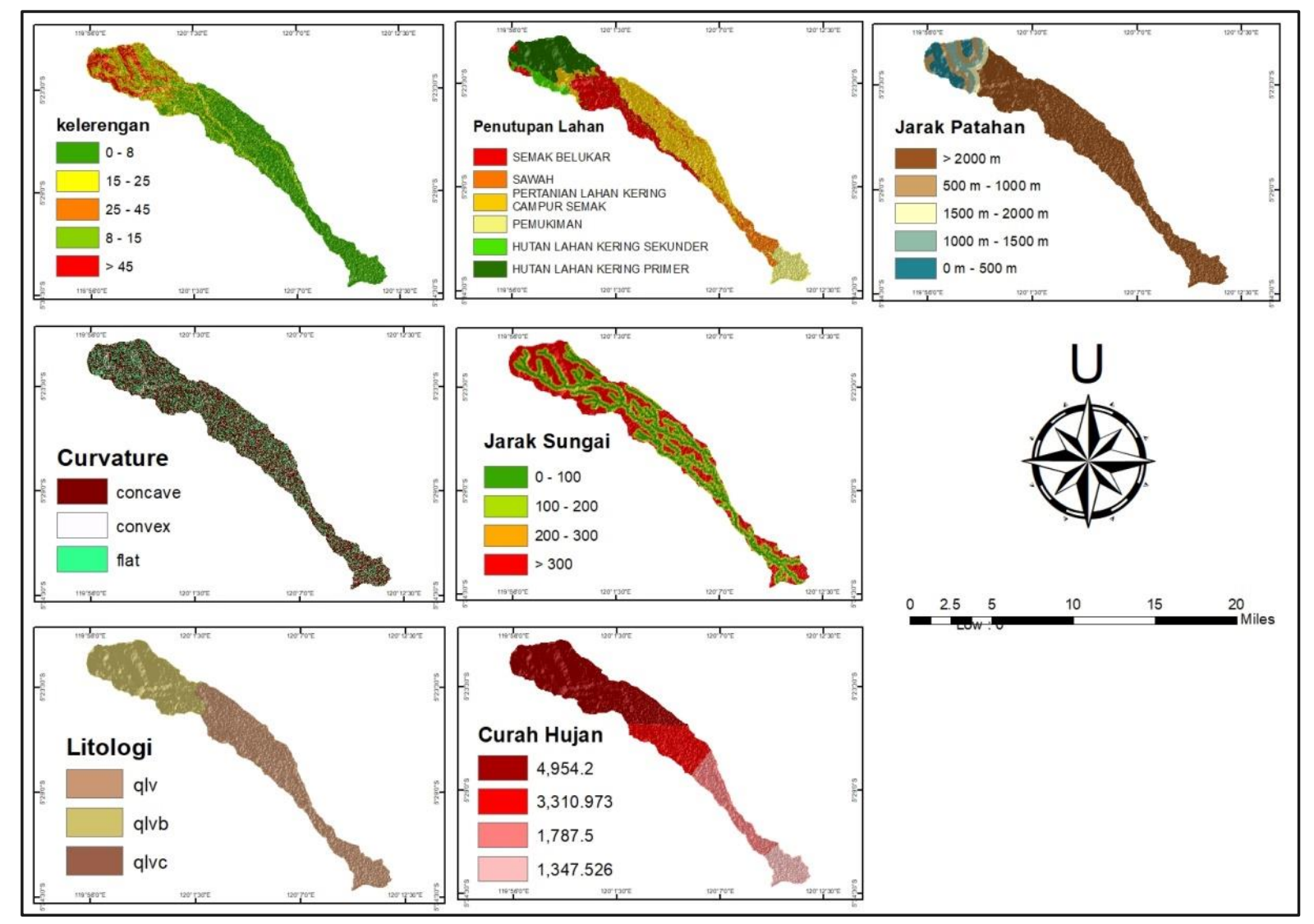

Gambar 3. Tujuh faktor penyebab longsor 


\section{Kemiringan Lereng}

Kemiringan lereng merupakan salah satu faktor yang sangat penting dalam proses terjadinya tanah longsor. Terjadinya suatu longsor sangat dipengaruhi oleh oleh tingkat kecuraman dan gaya pendorongnya terhadap material pada lereng tersebut. Jika kecuraman pada suatu lereng sangat tinggi maka gaya pendorongnya juga semakin besar. Tingkat kelerengan pada DAS Bialo dimulai dari tingkat kelerengan yang datar sampai tingkat kelerengan yang curam. Berdasarkan nilai frekuensi rasio, terdapat beberapa kelas kelerangan yang terlihat pada Gambar 4.

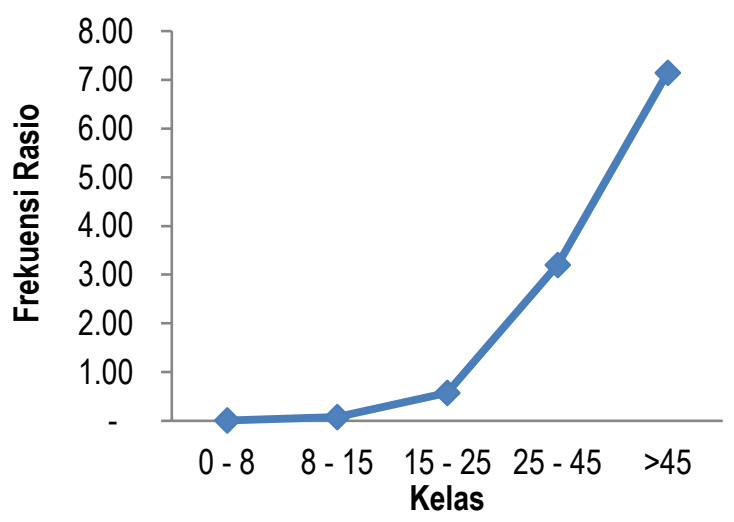

Gambar 4. Niai frekuensi rasio kelas kelerengan

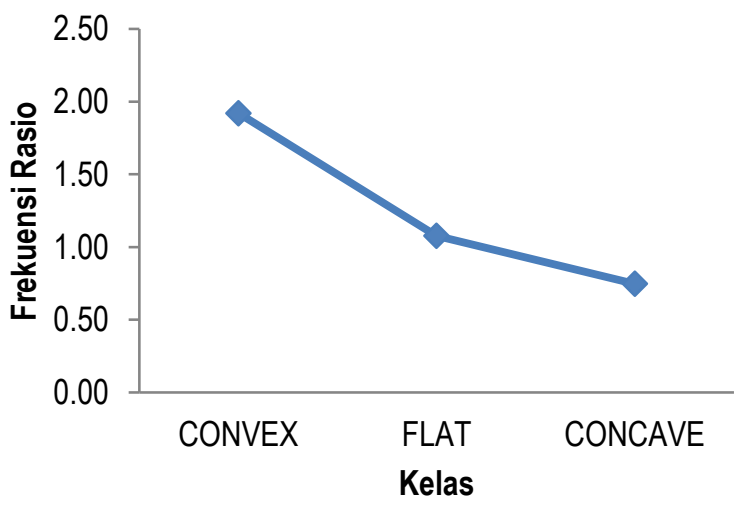

Gambar 5. Nilai frekuensi rasio kelas kurvatur

Di kelas lereng, kemiringan di atas $>45$ memiliki rasio $>1$ yang menunjukkan probabilitas tinggi terjadinya longsor. selain itu, kemiringan 0 - 8 memiliki rasio $<1$ yang menunjukkan kemungkinan terjadinya tanah longsor yang sangat rendah. Semakin curam lereng suatu lahan maka semakin besar dan semakin cepat longsor terjadi, hal ini bisa disebabkan karena besarnya gaya pendorong dan perngaruh gaya gravitasi terhadap material yang terdapat pada lereng tersebut. Tetapi tidak semua lahan berlereng curam berpotensi terjadinya longsor tergantung pada materi penyusunnya, dan responnya terhadap faktor penyebab lainnya seperti curah hujan dan penutupan lahan.

\section{Kurvatur (Kelengkungan Bumi)}

Nilai-nilai pada kelas kurvatur atau kelengkungan bumi mewakili morfologi topografi. Cembung menunjukkan nilai positif, cekung menunjukkan negatif, dan nilai nol menunjukkan permukaan datar. Terdapat 3 kelas kurvatur yaitu convex (cembung), flat (datar), dan concave (cekung), yang berdasarkan nilai frekuensi rasio dapat dilihat pada Gambar 5.

Berdasarkan grafik diatas terlihat bahwa nilai rasio frekuensi cembung $(1,92)$ memiliki kemungkinan tanah longsor lebih tinggi daripada cekung $(0,75)$ dan datar $(1,08)$. Nilai diatas menunjukkan bahwa pada bidang tanah yang datar pun bisa mengalami longsor. Nandi (2007) mengemukakan bahwa salah satu jenis longsor yang terjadi pada bidang datar yaitu longsoran translasi dimana longsoran ini merupakan pergerakan massa tanah dan batuan pada bidang tergelincir berbentuk rata atau menggelombang landai. Berdasarkan hasil pengamatan di lapangan, hal yang menjadi penyebab pada daerah datar di DAS Bialo cenderung berpengaruh terhadap terjadinya longsor dikarenakan terdapat akses jalan yang selalu digunakan oleh masyarakat ke lokasi perkebunan dalam menunjang tingkat perekonomian, sehingga tanah datar yang berada diatas perbukitan menjadi tanah terbuka. Hal ini menyebabkan hilangnya tanaman penutup tanah sebagai penghambat air hujan terlebih di daerah hulu memiliki tingkat curah hujan yang tinggi sehingga pengaruhnya terhadap terjadinya tanah longsor juga semakin besar.

\section{Litologi}

Uraian kondisi geologi berdasarkan pada Peta Geologi Lembar Ujung Pandang, Benteng, dan Sinjai, Sulawesi (Sukamto \& Supriatna, 1982) di DAS Bialo terdiri atas 3 kelompok batuan yaitu Batuan Gunung api Lompobattang (qlvb), Pusat Erupsi Gunung Api Lompobattang (qlvc) dan Batuan Gunungapi Lompobattang Terutama Lava dan Aglomerat (qlv). Berdasarkan peta litologi pada DAS Bialo, terdapat beberapa kelas litologi yang terlihat pada Gambar 6 .

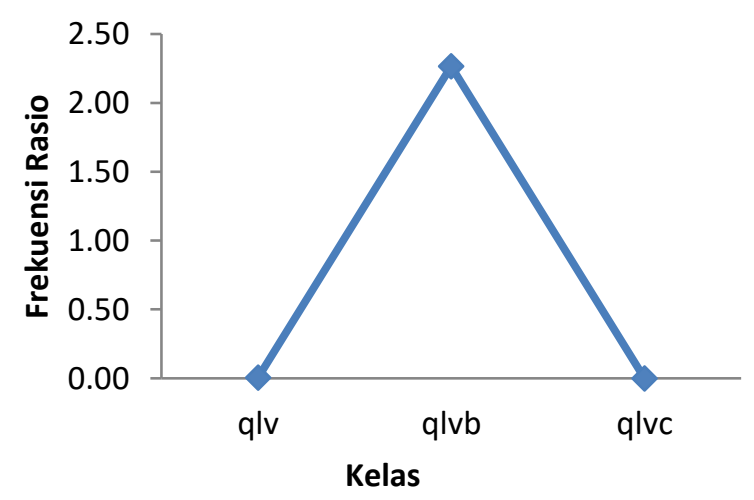

Gambar 6. Nilai frekuensi rasio kelas litologi 
Tanah longsor akibat aktivitas gunung api adalah salah satu yang paling faktor yang berpengaruh. Berdasarkan pengamatan menggunakan metode frekuensi rasio, Batuan Gunung api Lompobattang (qlvb) yaitu endapan lahar dan tufa memiliki rasio $>1$, yang menunjukkan kemungkinan tinggi terjadinya tanah longsor. Hal ini dikarenakan tufa merupakan salah satu endapan vulkanik yang mudah lapuk dari lapuk tinggi sampai lapuk sempurna, sehingga pada saat musim hujan air akan meresap ke dalam batuan dan menyebabkan massa batuan bertambah berat sehingga berpotensi terjadi tanah longsor (Arsyad et al., 2018). Batuan Gunung api Lompobattang yang merupakan salah satu formasi vulkanik dan sedimen di Sulawesi Selatan (qlv) dan Pusat erupsi gunung api lombobattang (qlvc) yang memperlihatkan bentuk kubah lava. Qlv dan qlvc memiliki rasio $<1$ yang berarti pengaruh nya terhadap longsor tergolong rendah. Menurut Djamaluddin (2003) tanah longsor di Indonesia umumnya terjadi di lereng terjal yang terbentuk dari endapan vulkanik yang tidak terpadatkan.

\section{Penutupan Lahan}

Penutupan lahan yang digunakan untuk faktor penyebab tanah longsor yaitu citra landsat 7 tahun 2003 yang kemudian didigitasi menghasilkan beberapa penutupan lahan. Berdasarkan peta penutupan lahan pada DAS Bialo, terdapat beberapa kelas penutupan lahan diantaranya hutan lahan kering primer, hutan lahan kering sekunder, pemukiman, pertanian lahan kering campur semak, sawah dan semak belukar. Grafik nilai frekuensi rasio berdasarkan kelas penutupan lahan dapat dilihat pada Gambar 7.

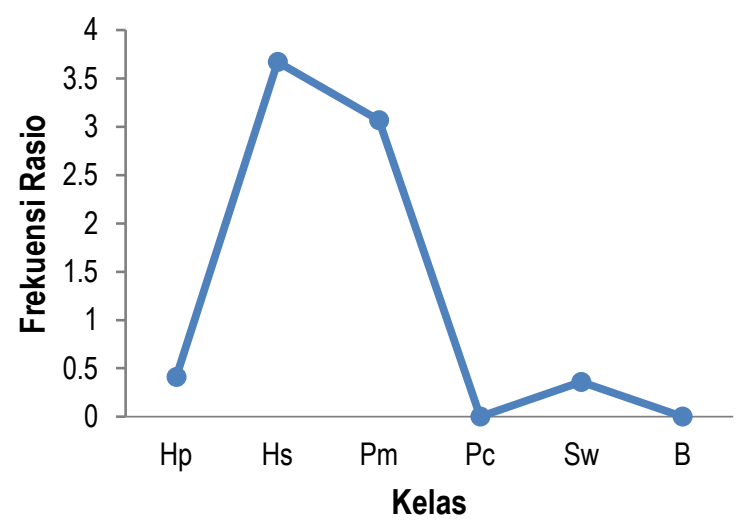

Gambar 7. Nilai frekuensi rasio kelas penutupan lahan (Hp adalah hutan ahan kering primer; $\mathrm{Hs}$ adalah hutan lahan kering sekunder; Pm adalah pemukiman; Pc adalah pertanian lahan kering campur semak; Sw adalah sawah; dan B adalah Semak belukar)

Berdasarkan hasil pengamatan penutupan lahan yang didapatkan, terdapat beberapa vegetasi yang bisa menyebabkan terjadinya tanah longsor. Pada penutupan hutan lahan kering sekunder dengan luas 365,28 ha memiliki nilai frekuensi tergolong tinggi yaitu $>1$. Dari hasil pengamatan di lapangan, hutan lahan kering sekunder berada pada wilayah kemiringan lereng yang agak curam dan curam. Selain itu, masyarakat juga ditemukan masih melakukan aktivitas perkebunan, seperti jagung dan cengkeh. Tanaman-tanaman tersebut memiliki sistem perakaran yang tidak kuat di dalam tanah sehingga menyebabkan potensi terjadinya tanah longsor lebih besar terutaman pada saat curah hujan tinggi.

Penutupan hutan lahan kering primer dengan luas $2.151,68$ ha dengan nilai rasio $<1$ yang berarti probabilitas terhadap terjadinya tanah longsor tergolong rendah. Vegetasi yang mendominasi di area tersebut yaitu areal yang vegetasinya masih alami. Vegetasi yang biasa dijumpai pada areal ini adalah Sengon (Albizia chinensis), galatiri, Damar laki (Araucaria canninghamii), Damar Gana (Spergula arvensis), Lutuh, Lossongg dan Balanteh, selain itu tutupan vegetasi yang masih rapat dan memiliki perakaran kuat yang dapat menahan air hujan dan bisa mencegah penjenuhan material di lereng.

Pertanian lahan kering campur semak dengan luas 3.965,04 ha berisi komoditas cengkeh, kopi, jagung memiliki nilai rasio < 1 . DAS Bialo khusus kawasan tersebut kebanyakan berada pada daerah landai dan datar sehingga tidak terlalu berpengaruh terhadap kejadian longsor.

Daerah pemukiman merupakan bagian dari penutupan lahan yang digunakan untuk memenuhi kebutuhan primer masyarakat. Luas pemukinan DAS bialo yaitu 1.039,06 ha memiiki nilai rasio $>1$. Pemukiman yang berada pada daerah datar dan daerah curam memiliki potensi longsor yang berbeda. Khususnya pemukiman yang berada di wilayah lereng curam baik di daerah lerengnya maupun daerah datar tetapi berada di bawah tanah berlereng curam akan sangat berpotensi terkena dampak longsoran.

Daerah persawahan pada DAS Bialo memiliki luas $1.106,59$ ha dengan nilai rasio $<1$. wilayah persawahan kebanyakan berada pada lereng yang datar hingga landai sehingga tidak terlalu berpengaruh terhadap terjadinya longsor.

Semak belukar memiliki luas $2.303,57$ ha dengan nilai frekuensi rasio $<1$. Semak belukar juga merupakan salah satu penutupan yang memicu terjadinya tanah longsor karena sistem perakaran tumbuhan semak belukar sangat tidak bagus dalam artian kemampuannya dalam mengikat tanah sangat rendah.

\section{Jarak dari Sungai}

Faktor penyebab longsor untuk jarak ke sungai, rasio jarak/kedekatan digunakan untuk memahami tingkat pengaruh pada tanah longsor. Berdasarkan peta jarak dari sungai pada DAS Bialo yang dianalisis dari DEM Nasional, terdapat beberapa kelas jarak dari sungai yang dapat dilihat pada Gambar 8. 


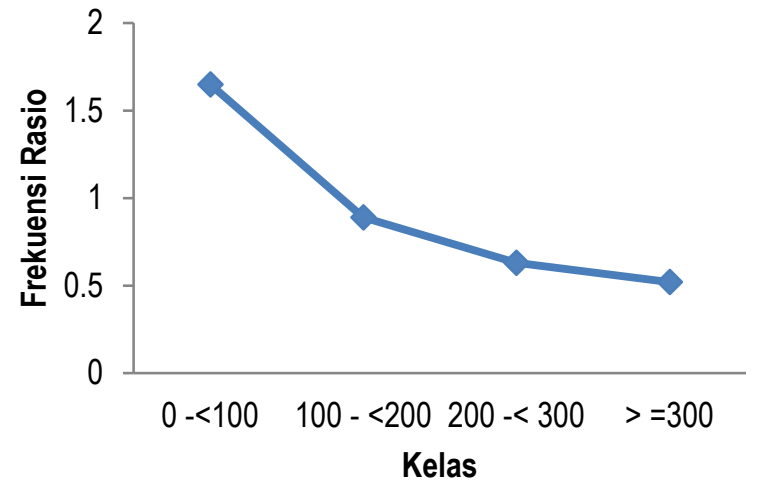

Gambar 8. Nilai frekuensi rasio kelas jarak dari sungai

Untuk jarak ke sungai di $0-<100 \mathrm{~m}$ memiliki rasio frekuensi $>1$ dan di kelas $>=300 \mathrm{~m}, 200-<300 \mathrm{~m}$, dan 100 $<200$ m memiliki rasio < 1, ini menunjukkan kemungkinan terjadinya tanah longsor akan meningkat jika jarak ke sungai lebih dekat.

\section{Jarak dari Patahan}

Faktor penyebab untuk jarak ke patahan sama seperti jarak ke sungai yaitu rasio jarak kedekatan digunakan untuk memahami tingkat pengaruh pada tanah longsor. Berdasarkan peta jarak dari patahan/sesar pada DAS Bialo yang dianalisis dari Peta Geologi Lembar Ujung Pandang, Benteng, dan Sinjai, Sulawesi (Sukamto \& Supriatna, 1982) terdapat beberapa kelas jarak dari sungai yang dapat dilihat pada Gambar 9.

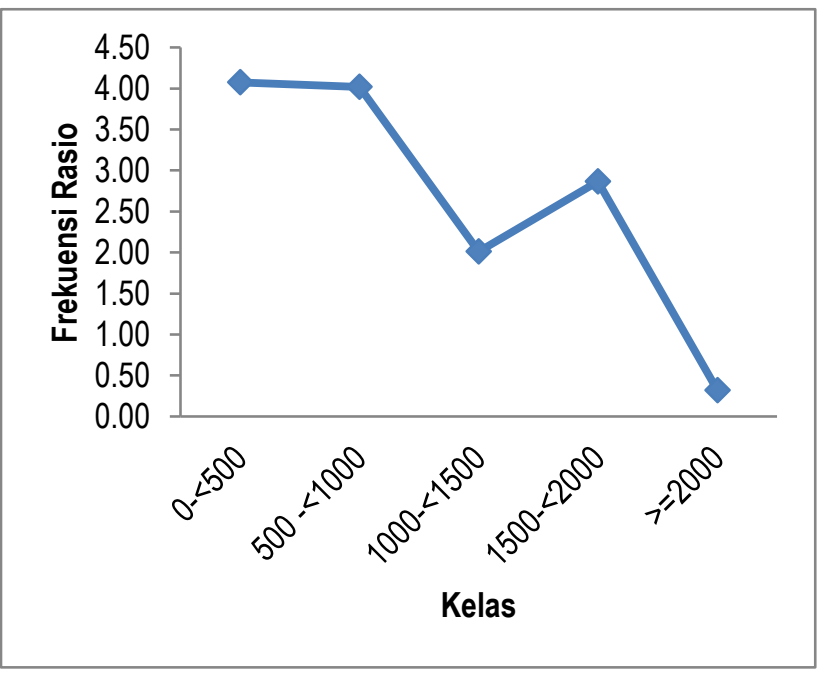

Gambar 9. Nilai frekuensi rasio kelas jarak dari patahan

Jarak ke patahan di $0-<500 \mathrm{~m}, 500-<1.000 \mathrm{~m}, 1.000$ $<1.500 \mathrm{~m}$, dan kelas $1.500-<2.000 \mathrm{~m}$ memiliki rasio $>1$ dan jarak ke patahan $>=2.000 \mathrm{~m}$ memiliki rasio $<1$. Hal Ini menunjukkan bahwa semakin dekat jarak ke patahan, maka kemungkinan terjadinya tanah longsor akan meningkat, terlebih jika terdapat patahan aktif dan saling bergesekan yang bisa menyebabkan patahan semakin terbuka dikarenakan menghilangnya kekuatan tanah sehingga tingkat terjadinya tanah longsor semakin meningkat.

\section{Curah Hujan}

Curah hujan merupakan salah satu unsur iklim yang memiliki peran besar terhadap terjadinya tanah longsor. Data curah hujan yang diambil dari Badan Meteorologi, Klimatologi, dan Geofisika (BMKG) Sulawesi Selatan periode 2004-2014 kemudian dianalisis menggunakan metode polygon Thiessen. Stasiun curah hujan di DAS Bialo terbagi atas 4 stasiun yaitu BPP. Tanah Kongkong, Borong Rappoa, Bonto Macinna dan Tompobulu/Banyorang dengan masing-masing stasiun memiliki curah hujan yang berbeda. Grafik curah hujan di DAS Bialo dapat dilihat pada Gambar 10.

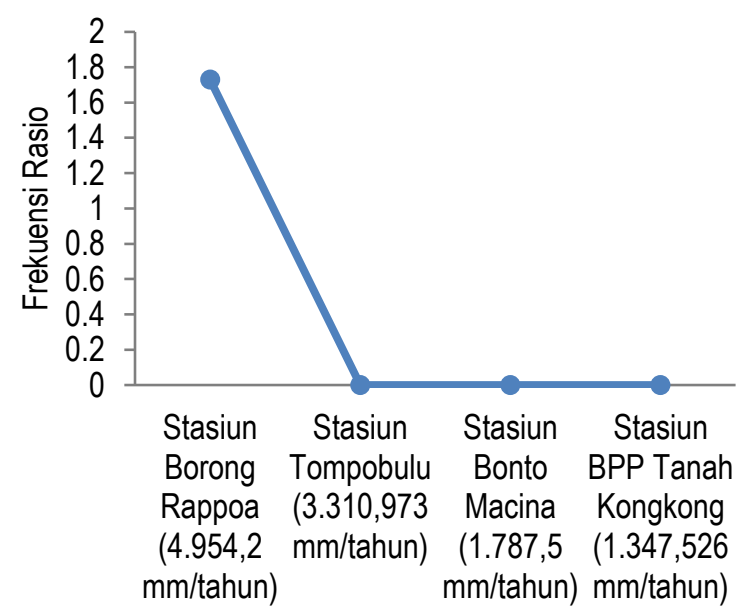

Gambar 10. Nilai frekuensi rasio curah hujan

Pada curah hujan yang tertinggi yaitu $4.954,2$ $\mathrm{mm} /$ tahun memiliki rasio $>1$ yang menunjukkan probabilitas tinggi terjadinya longsor, selain itu curah hujan $3.310,973 \mathrm{~mm}$, curah hujan $1.787,5 \mathrm{~mm} / \mathrm{tahun}$ dan curah hujan terendah yatu $1.347,526 \mathrm{~mm} /$ tahun memiliki rasio $<1$.

Selain itu, hal ini mengindikasikan bahwa lebih banyak presipitasi yang terjadi pada suatu wilayah akan menyebabkan lebih banyak kejadian tanah longsor. Aditian dan Kubota (2017) menunjukkan bahwa peningkatan tingkat curah hujan memungkinkan tanah menjadi tidak stabil dan rentan terhadap bencana tanah longsor. Hal ini kemudian diperkuat oleh Hasnawir et al. (2017) yang menunjukkan bahwa intensitas curah hujan sangat berpengaruh terhadap kejadian tanah longsor yang di dukung oleh faktor penyebab lainnya.

\section{Validasi Tanah Longsor di DAS Bialo berdasarkan Metode Frekuensi Rasio}

Berdasarkan peta tingkat kerawanan longsor diatas, terdapat 5 klasifikasi tingkat kerawanan longsor yaitu sangat rendah, rendah, sedang, tinggi, sangat tinggi. Daerah hulu DAS Bialo merupakan lokasi yang memiliki 


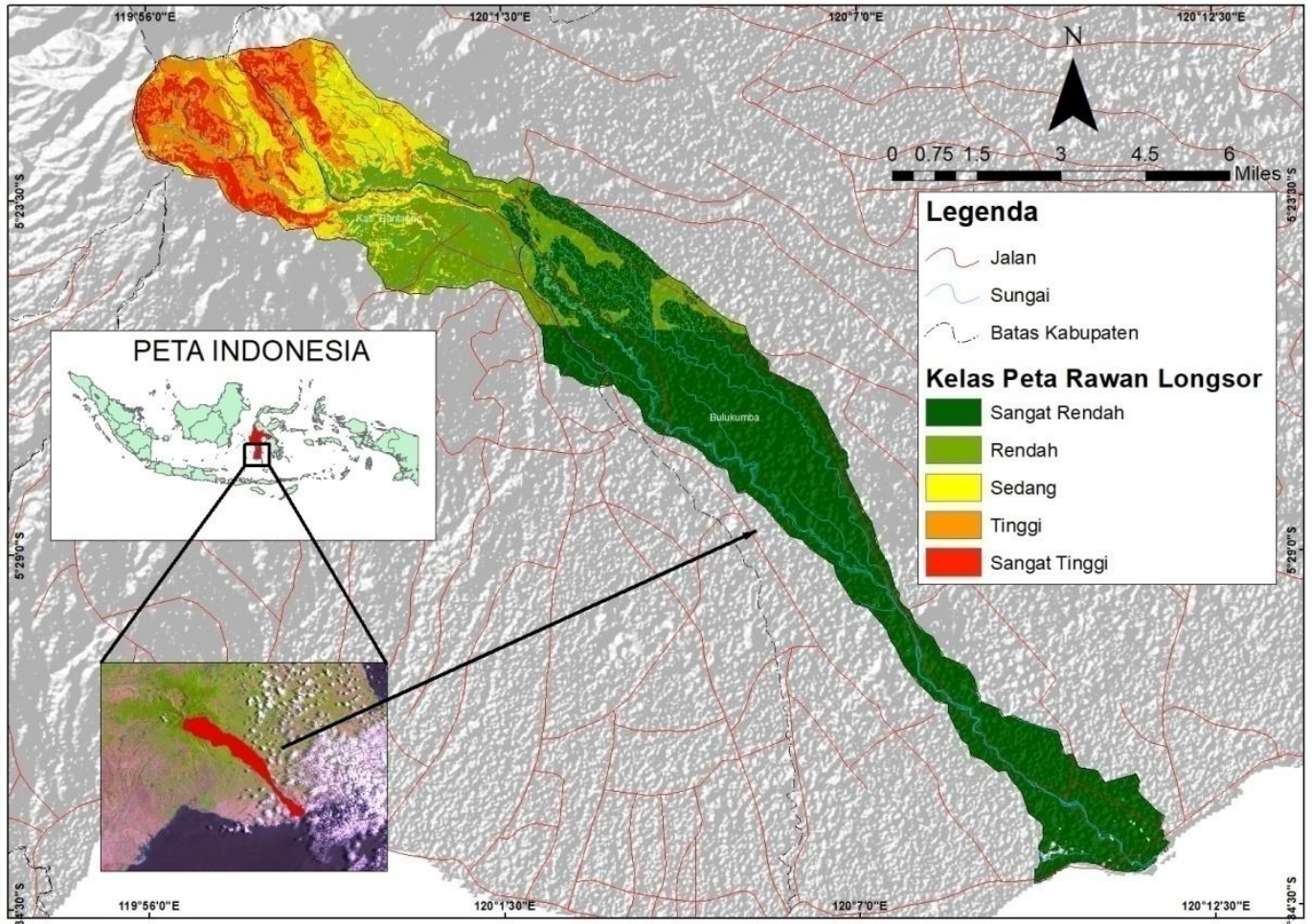

Figure 11. Peta kerawanan longsor

tingkat kerawanan longsor pada kelas yang sangat tinggi, tinggi, dan sedang. Sedangkan daerah hilir DAS Bialo merupakan lokasi yang memiliki tingkat kerawanan longsor pada kelas yang rendah dan sangat rendah. Masing - masing luas kelas kerawanan pada DAS Bialo dapat terlihat pada gambar 11.

Kelas kerawanan sangat rendah memiliki luas $51 \%$ (5.690,31 ha), kelas kerawanan rendah memliki luas 19\% (2.159,55 ha), kelas kerawanan sedang memiliki luas $11 \%$ $(1.315,12 \mathrm{ha})$, kelas kerawanan tinggi dengan luas $12 \%$ $(1.410,08 \mathrm{ha})$, dan kelas kerawanan sangat tinggi yang luasnya hanya sekitar $7 \%$ (823,06 ha) dari total luas DAS Bialo yaitu 10.948,4 ha. Perbandingan antara luas kelas kerawanan sangat rendah dan kelas kerawanan sangat tinggi terlihat sangat berbeda dimana luas kelas kerawanan sangat rendah masih lebih mendominasi di DAS Bialo. Tetapi data tersebut bukan berarti bahwa potensi longsor di DAS Bialo tergolong rendah karena dari luas kelas kerawanan sangat tinggi, potensi longsor kebanyakan terjadi di daerah hulu DAS Bialo dan kelas kerawanan sangat rendah kebanyakan terjadi di bagian tengah dan hilir DAS Bialo.

\section{KESIMPULAN}

Berdasarkan hasil inventarisasi kejadian tanah longsor periode tahun 2004 - 2014, jumlah tanah longsor yang diidentifikasi di DAS Bialo sebanyak 216 poligon. Analisis menggunakan frekuensi rasio, menunjukkan bahwa pada kelas faktor kemiringan lereng, daerah dengan kemiringan $>45$ memiliki probabilitas terjadinya longsor yang paling tinggi diantara faktor lainnya dengan nilai frekuensi rasio sebesar 7,15. Berdasarkan peta kerawanan tanah longsor, dapat dilihat bahwa daerah yang memiliki tingkat kerawanan longsor yang sedang sampai sangat tinggi berada pada daerah hulu dengan masing masing luas $11 \%, 12 \%$ dan $7 \%$ dari total luas DAS Bialo, sedangkan daerah dengan tingkat kerawanan rendah sampai sangat rendah berada pada daerah hilir dengan masing masing luas $19 \%$ dan $51 \%$ dari total luas DAS Bialo .

\section{DAFTAR PUSTAKA}

Aditian, A., \& Kubota, T. (2017). The influence of Increasing Rainfall Intensity on Forest Slope Stability in Aso Volcanic Area, International Journal of Ecology and Development, Vol. 32, 1, 2017.01.

Arsyad, U., Barkey, R., Wahyuni, \& Matandung, K. K. (2018). Karakteristik Tanah Longsor di Daerah Aliran Sungai Tangka. Jurnal Hutan dan Masyarakat, Vol. 10 (1): 203-214.

Badan Nasional Penanggulangan Bencana. (2018). Retrieved Oktober 27, 2018, from Data Informasi Bencana Indonesia (DIBI) Tahun 2013-2017: http://dibi.bnpb.go.id/dibi/

Djamaluddin, R. (2003). Fundamental study on application of unresin continuous carbon fiber reinforcing system to concrete structures. Institusi Nasional Informasi Scholary dan Navigator Informasi Akademik CiNii, 927-934.

Handayani, L., \& Singarimbun, A. (2016). Pemetaan Daerah Rawan Longsor di Sekitar Daerah Prospek Panas Bumi Provinsi Jawa Barat. JoP, Vol. 2 NO. 1, November 2016, 17-22.

Hasnawir, Kubota, T., Sanchez-Castillo, L., \& Soma, A. S. (2017). The Influence of Land Use and Rainfall on Shallow Landslides in 
Tanralili Sub-watershed, Indonesia. Journal Faculty Agriculture, Kyushu University, 62 (1), 171-176.

Nandi. (2007). Longsor. Bandung: Jurusan Pendidikan Geografi, FPIPS-UPI.

Nusantara, Y., \& Setianto, A. (2015). Pemetaan Bahaya Tanah Longsor dengan Metode Frequency Ratio di Kecamatan Piyungan dan Pleret, Kabupaten Bantul, Daerah Istimewa Yogyakarta. Proceeding, Seminar Nasional Kebumian Ke-8 (15-16 Oktober 2015) (pp. 513-522). Academia-Industry Linkage; Graha Sabha Pramana.

Pradhan, B., \& Lee, S. (2010). Landslide susceptibility assessment and factor effect analysis: backpropagation artificial neural networks and their comparison with frequency ratio and bivariate logistic regression modelling. Environmental Modelling \& Software, 747-759.
Soma, A. S., \& Kubota, T. (2017). The Performance of Land Use Change Causative Factor on Landslide Susceptibility Map in Upper Ujung-Loe Watersheds South Sulawesi, Indonesia. Journal of Geomatics and Planning, 157-170.

Sukamto, R., dan Supriatna, S., (1982). Peta Geologi Bersistem Lembar Ujungpandang, Benteng, dan Sinjai Sulawesi, Pusat Penelitian Dan Pengembangan Geologi, Bandung.

Tanika, L., Wijaya, C. I., Dwiyanti, E., \& Khasanah, N. (2013). Peranan Lahan Berbasis Agroforestri Terhadap Neraca Air. Prosiding Seminar Nasional Agroforestri 2013, (pp. 328-334). 